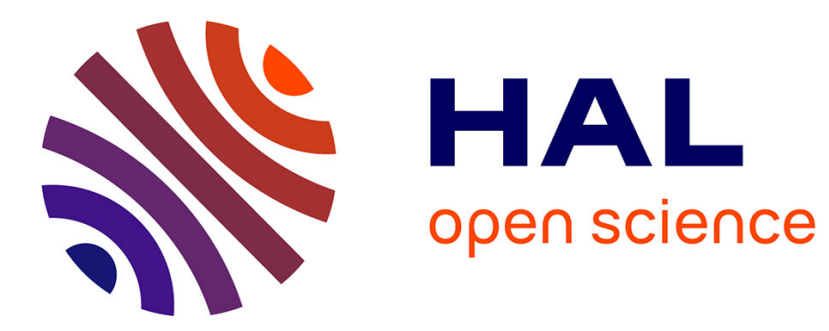

\title{
A Novel approach to Extract the Thyristor Design Parameters for Designing of Power Electronic Systems
}

\author{
Atef Jedidi, Hatem Garrab, Hervé Morel, Kamel Besbes
}

\section{To cite this version:}

Atef Jedidi, Hatem Garrab, Hervé Morel, Kamel Besbes. A Novel approach to Extract the Thyristor Design Parameters for Designing of Power Electronic Systems. IEEE Transactions on Industrial Electronics, 2015, 62 (4), 10.1109/TIE.2014.2356440 . hal-01388299

\section{HAL Id: hal-01388299 https://hal.science/hal-01388299}

Submitted on 18 Nov 2019

HAL is a multi-disciplinary open access archive for the deposit and dissemination of scientific research documents, whether they are published or not. The documents may come from teaching and research institutions in France or abroad, or from public or private research centers.
L'archive ouverte pluridisciplinaire HAL, est destinée au dépôt et à la diffusion de documents scientifiques de niveau recherche, publiés ou non, émanant des établissements d'enseignement et de recherche français ou étrangers, des laboratoires publics ou privés. 


\title{
A Novel Approach to Extract the Thyristor Design Parameters for Designing of Power Electronic Systems
}

\author{
Atef Jedidi, Hatem Garrab, Member, IEEE, Hervé Morel, Senior Member, IEEE, and Kamel \\ Besbes, Member, IEEE
}

\begin{abstract}
Accurate simulation is an essential task in designing of integrated power systems to predict their electrical behavior. Thus, a very good description of their wiring circuits is required, and the availability of accurate models of power semiconductor devices and associated design parameters is crucial. This paper focuses on a novel extraction approach of design parameters for a 1-D finite-element-method model of the thyristor. These design parameters are also essential for physics-based analytical models. This paper presents an extraction procedure of the main design parameters of an ultrafast thyristor: the effective area of the device, the ambipolar lifetime, the doping concentration and width of the low-doped base region, and the doping concentration and width of the gate region. The extraction procedure of the thyristor design parameter is based on a comparative computation between simulation and experimental results, taking into account the physics of the component. Measurements are carried out on a sophisticated test circuit, which must be modeled with a sufficient accuracy. This paper details the parameter extraction procedure. Various electrothermal simulation results about the thyristor under test, using the extracted values of design parameters, show good agreement with experiment and confirm the validity of the presented extraction procedure.
\end{abstract}

Index Terms- Modeling, Finite Element Method (FEM), Thyristors, Simulation.

\section{INTRODUCTION}

$\mathrm{T}_{\mathrm{b}}^{\mathrm{H}}$ Hyristors and gate turn-off thyristors (GTOs) continue to be used in power electronic applications particularly for high power application [1]-[6]. Thyristors are also available as new silicon carbide devices with strong capabilities [7][9]. However, silicon devices are further available at lower cost. Therefore, the availability of thyristor models is highly recommended for the analysis and design of power electronic systems, including thyristors and even GTO. Modeling and

Manuscript received February 21, 2014; revised May 10, 2014; accepted July 29, 2014.

Copyright (c) 2014 IEEE. Personal use of this material is permitted. However, permission to use this material for any other purposes must be obtained from the IEEE by sending a request to pubspermissions@ieee.org.

A. Jedidi, H. Garrab, and K. Besbes are with the Microelectronics and Instrumentation Laboratory (LR13ES12), Department of Physics, Science Faculty of Monastir, University of Monastir, 5000 Monastir, Tunisia (e-mail: atef_jdidi@yahoo.fr; garhat@yahoo.fr; kamel.besbes@ fsm.rnu.tn).

$\mathrm{H}$. Morel is with the Ampere Laboratory, University of Lyon [Insti- tut National des Sciences Appliquées (INSA)], Centre National de la Recherche Scientifique (CNRS), 69621 Villeurbanne, France (e-mail: Herve.Morel@insa-lyon.fr). simulation are an essential part of the design flow of power electronic systems. The modeling is used to consider nonmeasurable amounts of real devices, to optimize the realization cost and to increase the reliability of designed circuits. A precise description of power system behavior requires the availability of accurate component models. The validity of the semiconductor device models depends not only on semiconductor equations but also on device design parameters, i.e., the structure definition. Since it is difficult to obtain these parameters directly from the manufacturers, the extraction of these parameters may be based on reverse engineering techniques, but it remains a sensitive and a destructive task. There is therefore great interest in the development of nondestructive extraction and appropriate methods to obtain accurate models of power devices [10][15]. This paper describes a step-by-step extraction procedure to identify the main design parameters of a thyristor. This is a first step toward the design and optimization of power electronic systems using thyristors and GTO based on silicon or silicon carbide materials dedicated to transportation systems and power distribution and transmission of electricity.

Section II presents a state-of-the-art of the thyristor modeling and the selected modeling approach. Section III presents the model of the circuit used for the comparison between simulation and experiments. Section IV presents the extraction procedure. Section V presents some preliminary results and the analysis of the validity domain of the obtained parameters. This paper finishes by some conclusions.

\section{THYRISTOR MODELING}

Given the complexity of physical phenomena that governs thyristor operation, published model accuracy for such device is usually weak [16]-[20]. The SPICE model in [16] is not accurate since it does not consider the high-level injection phenomena in the thyristor epitaxial layer. Literature reports also models using lumped-charge techniques [18]-[20]. These models use localized charge method to get a pretty accurate description of the charge behavior in the component base region. These models as those based on finite-element methods (FEMs) depend on device design parameters.

The FEM is one of the most accurate approaches in power devices modeling. In this paper, the FEM is selected for thyristor modeling. The 2-D basic structure of a vertical power thyristor is presented in Fig. 1. It is based on a lightly doped N-type 


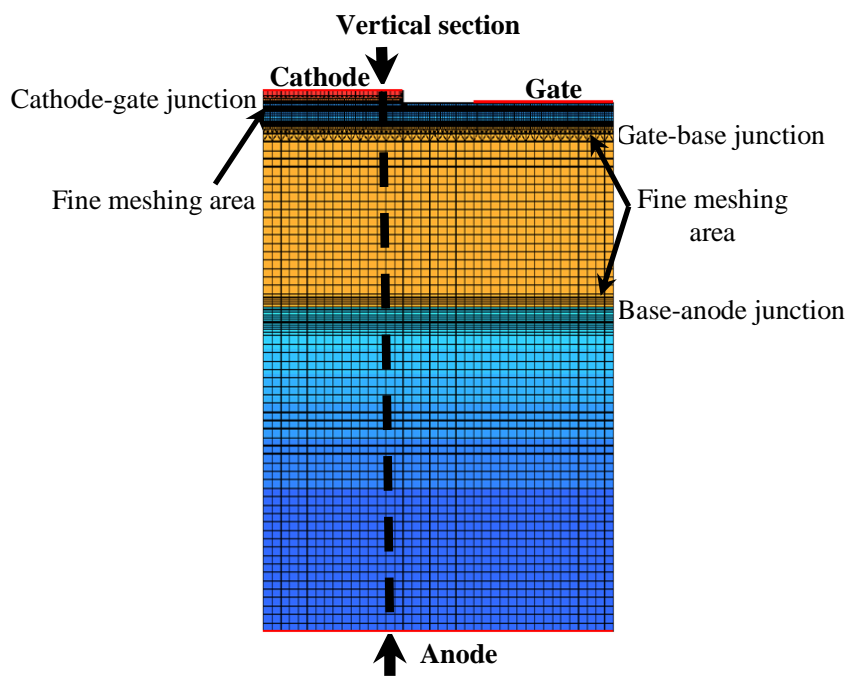

(a)

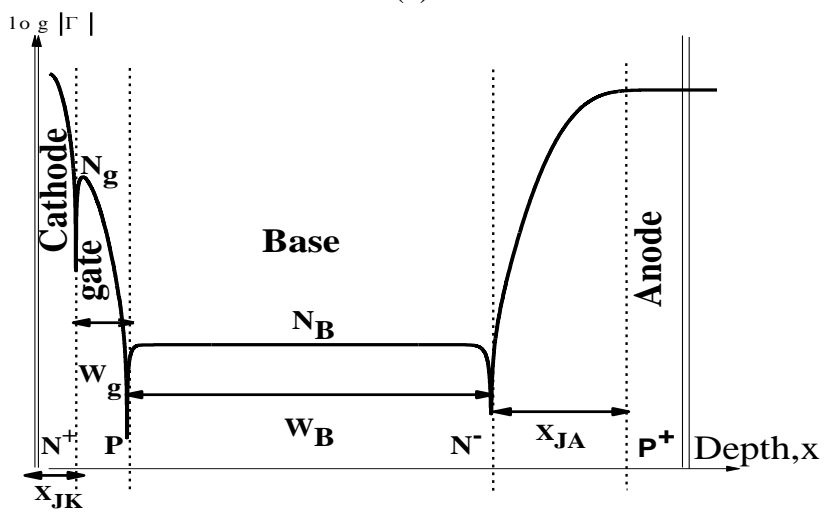

(b)

Fig. 1. Simplified 2-D architecture for the thyristor. (a) 2-D structure of a meshed thyristor. (b) Thyristor doping profile according a vertical section from cathode to anode as mentioned in (a)

TABLE I.

THYRISTOR DESIGN PARAMETERS

\begin{tabular}{l|l}
\hline Symbol & Definition \\
\hline $\mathbf{W}_{\mathbf{B}}(\boldsymbol{\mu m})$ & Width of the lightly doped base region of thyristor \\
\hline $\mathbf{N}_{\mathbf{B}}\left(\mathbf{c m}^{-3}\right)$ & Doping of the lightly doped base region of thyristor \\
\hline $\mathbf{W}_{\mathrm{g}}(\boldsymbol{\mu \mathbf { m }})$ & Width of the thyristor gate region \\
\hline $\mathbf{N}_{\mathrm{g}}\left(\mathbf{c m}^{-3}\right)$ & Doping concentration of the thyristor gate region \\
\hline $\mathbf{A}\left(\mathbf{m m}^{2}\right)$ & Thyristor effective area \\
\hline$\tau(\boldsymbol{\mu s})$ & Thyristor ambipolar lifetime \\
\hline $\mathbf{X}_{\mathbf{J A}}(\boldsymbol{\mu m})$ & Depth of the anode-base junction \\
\hline $\mathbf{X}_{\mathbf{J K}}(\boldsymbol{\mu m})$ & Depth of the cathode-gate junction \\
\hline $\mathbf{N}^{+}\left(\mathbf{c m}^{-3}\right)$ & Doping concentration of the thyristor cathode region \\
\hline $\mathbf{P}^{+}\left(\mathbf{c m}^{-3}\right)$ & Doping concentration of the thyristor anode region \\
\hline
\end{tabular}

layer (epitaxy or substrate), whose optimized for the blocking voltage of the device. The cathode region, the P-gate area and the anode region contacts, are respectively established on the front side and the back side of the wafer. Table I gives the list of the thyristor design parameters.

The main design parameters that characterize the arbitrary 1-D technological architecture of thyristor are shown in Fig. 1(b). Identification of the $\mathrm{N}^{+}$and $\mathrm{P}^{+}$regions is behind the scope of this paper since their impacts are of second order on the thyristor transient behavior except at very high current level where the lateral regions control the carrier injection [21].

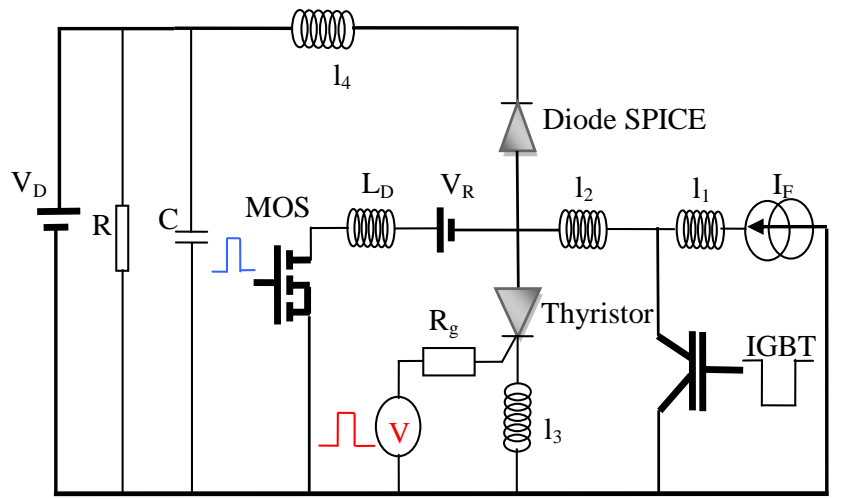

(a)

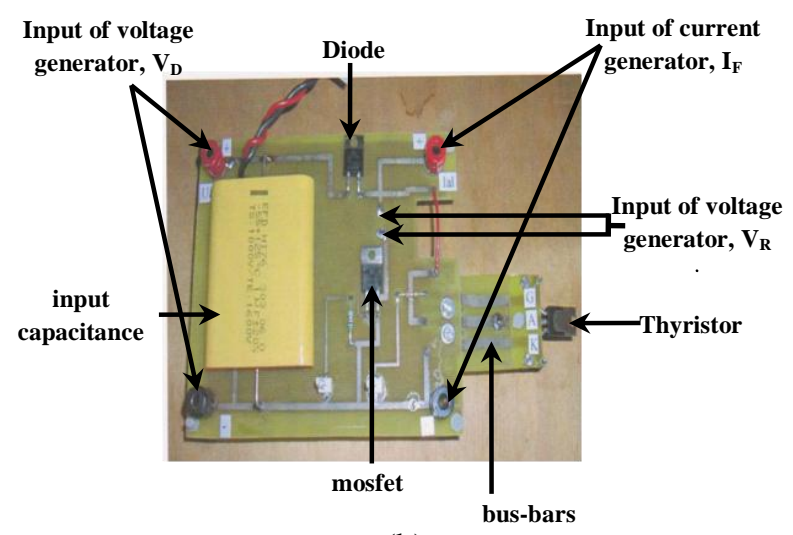

(b)

Fig. 2. Experimental circuit for the thyristor design parameter extraction. (a) Schematic. (b) Picture (IGBT transistor not included)

The secondary design parameters of thyristor $\mathrm{X}_{\mathrm{JA}}, \mathrm{X}_{\mathrm{JK}}, \mathrm{N}^{+}$ and $\mathrm{P}^{+}$are set arbitrarily as follows $\mathrm{X}_{\mathrm{JA}}=40 \mu \mathrm{m}, \mathrm{X}_{\mathrm{JK}}=2 \mu \mathrm{m}$, $\mathrm{P}^{+}=10^{20} \mathrm{~cm}^{-3}$ and $\mathrm{N}^{+}=10^{20} \mathrm{~cm}^{-3}$. These values are of the same order as those of commercial device technologies.

Using the graphical tool, MDRAW-ISE TCAD [22], the thyristor 2-D architecture presented in Fig. 1(a) is implemented in FEM simulator DESSIS-ISE TCAD [23]. A meshing tool is after used to produce the necessary data such as: geometric data structure and doping profile of the component which will be used by the simulator, DESSIS-ISE TCAD. A fine meshing is performed in gate-base, cathodegate and base-anode junctions and electrode contacts.

\section{CIRCUIT MODEL}

A sophisticated experimental circuit was designed to acquire the thyristor dynamic characteristics during its turn-off transient behavior, as shown in Fig. 2.

A switching cell using a MOSFET transistor and the device under test (DUT), the thyristor is implemented. In this circuit the MOSFET transistor is used to turn-off the thyristor. A current shunt in a wide bandwidth (from DC to AC $1.2 \mathrm{GHz}$ ) [24] is inserted in series with the thyristor. Two voltage probes, Tektronix P5100 [25], are selected. They are connected in differential manner to the thyristor to reduce the interference coming from the synchronous noise signal picked up by the probes [26]. The switching cell consists of two 


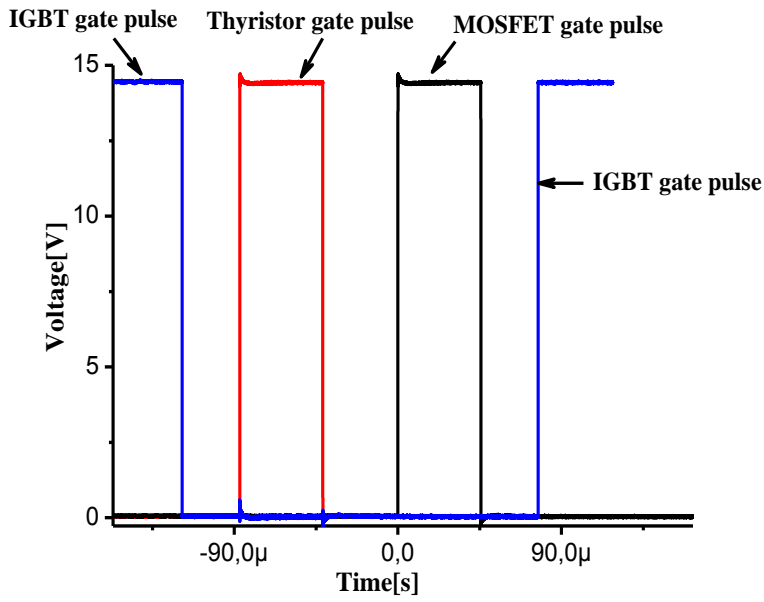

Fig. 3. Experimental control signal for IGBT, MOSFET and the thyristor gate.

voltage generators, a current generator, a MOSFET transistor, an insulated-gate bipolar transistor (IGBT), a p-i-n diode and a drive circuit, including a microcontroller delivering three synchronized pulses. These pulses are after amplified. These three obtained pulses are applied to the MOSFET transistor, the IGBT transistor and the DUT. The control timing diagram is shown in Fig. 3.

The IGBT transistor (MUP304) is turned-off only several tens of microsecond every hundreds of milliseconds and it is turned-on most of the time hence shorting the current source. The IGBT transistor enables to ensure the most part of power dissipation. Therefore, the self-heating of thyristor and MOSFET is avoided.

The experimental circuit is designed to give the best comparison condition between the measurements and the simulation obtained with the circuit model in Fig. 2. Hence, the experimental circuit includes two inductors $\left(I_{l}\right.$, airinductor) and $\left(I_{2}\right.$, core-inductor) in series with the current source, whose purpose to stabilize its current $I_{F}$ during switching. Polypropylene and ceramic capacitance is added in parallel with the voltage source to stabilize the applied voltage, $V_{D}$. The voltage source is not reversible in current, so resistance is added in parallel to the voltage generator $V_{D}$ to dissipate the average energy returned to the source and allows proper regulation of the voltage source. The IGBT transistor shorts the current source when a pulse is applied to its gate and the $\mathrm{I}_{\mathrm{F}}$ current is flowing through the IGBT. However, when the IGBT transistor is turned-off, the current flow in the PiN diode and the DUT is blocked and forward biased by the $V_{D}$ voltage. Once the thyristor gate is activated, the conduction process of component is triggered. Then, a pulse is applied to the MOSFET gate that turns-on and enforces the thyristor to turn-off in a recovery process. The duration of the pulse that switches the MOSFET should be long enough to avoid immediate turn-on of the thyristor under test at reapplication of the forward voltage. This is related to the TQ of the thyristor. Once the MOSFET is turned-on, the thyristor is reverse biased by the voltage generator $\left(\mathrm{V}_{\mathrm{R}}\right)$. Thereby, the stored charge in the thyristor base during its conduction phase will be evacuated and the reverse recovery phenomenon of thyristor starts. Experimental current and voltage waveforms

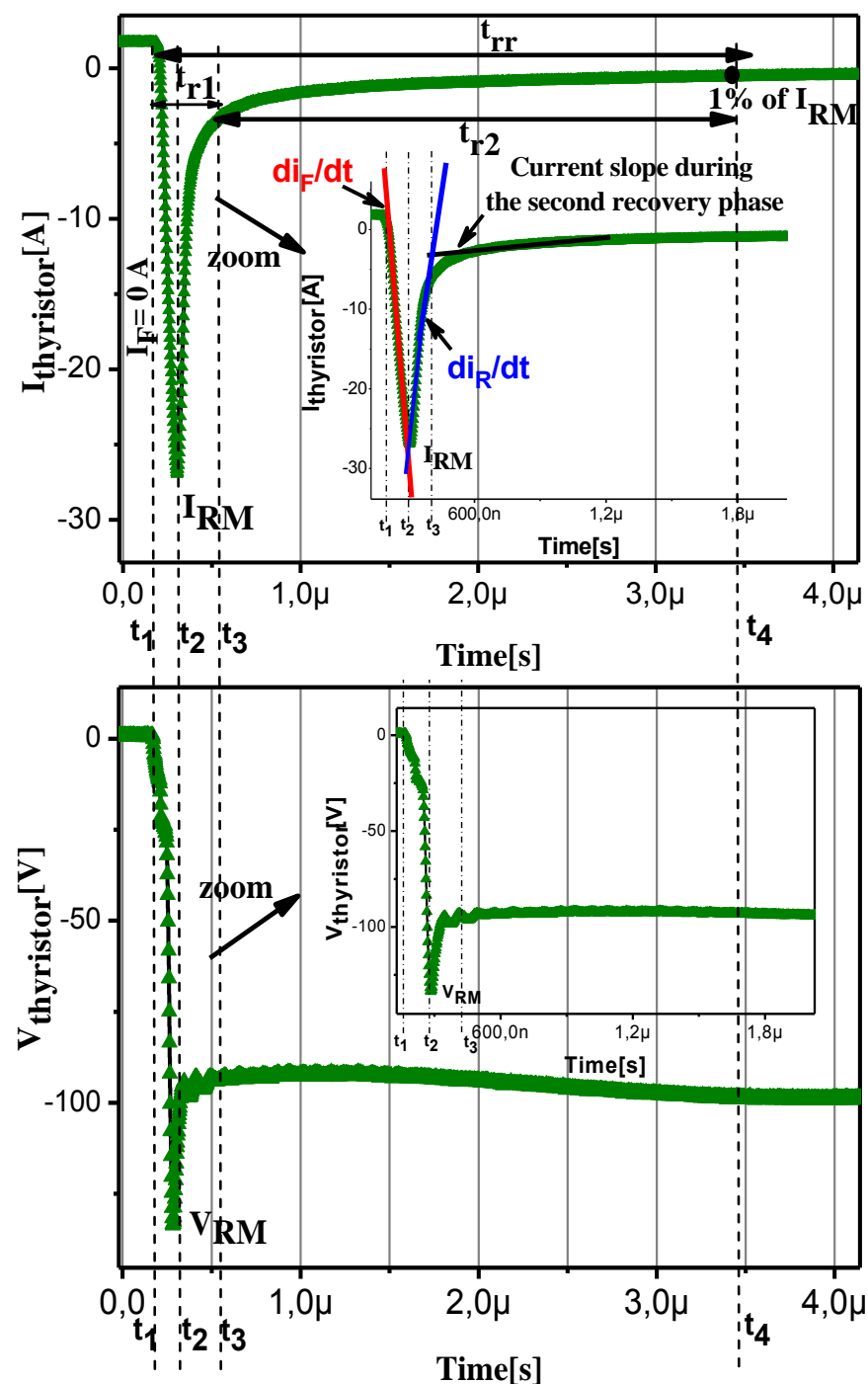

Fig. 4. Experimental current and voltage waveform across the Thyristor during its turn-off phase $\left(I_{F}=2 A\right.$ and $\left.V_{R}=100 V\right)$

TABLE II.

MAIN SWITCHING PARAMETERS OF THYRISTOR

\begin{tabular}{|c|c|}
\hline Symbol & Definition \\
\hline $\mathbf{I}_{\mathrm{RM}}(\mathrm{A})$ & Maximum reverse current of thyristor \\
\hline $\mathbf{V}_{\mathrm{RM}}(\mathbf{V})$ & Maximum reverse voltage of thyristor \\
\hline $\mathbf{t}_{\mathbf{r} 1}(\mu \mathrm{s})$ & $\begin{array}{l}\text { The first recovery time associated to the stored charge } \\
\text { recovery in the thyristor base }\end{array}$ \\
\hline $\mathbf{t}_{\mathrm{r} 2}(\mu \mathrm{s})$ & $\begin{array}{l}\text { the second reverse recovery time associated to recovery } \\
\text { of the stored charge amount remaining in the thyristor } \\
\text { gate and base region }\end{array}$ \\
\hline$t_{\mathrm{rr}}(\mu s)=t_{r 1}+t_{r 2}$ & Total reverse recovery time of thyristor \\
\hline
\end{tabular}

across the thyristor during its turn-off phase are shown in Fig. 4. On these transient behavior characteristics, main switching parameters of thyristor are defined and they are illustrated in Table II.

Main switching parameters will be useful for the extraction procedure since they characterize the simulated and experimental waveforms of current and voltage across the component during its turn-off phase.

During the thyristor conduction phase, a high-level injection regime is established in the central region of the device. As for the p-i-n diode, the integration of continuity equations for holes and electrons gives the amount of the stored charge, i.e., 
$Q_{0}=\tau \cdot I$. To turn off the thyristor, all the stored charge should be evacuated. However, during the device turn-off phase, one part of this stored charge is recombined inside the component. The remaining amount called recovery charge is evacuated due to the reverse current. The evacuation process of this recovery charge is decomposed into two parts. Initially, a portion of this charge $Q_{1}$ that has been already stored in the thyristor base region is recovered from instant $t_{1}$ to $t_{3}$. From $t_{1}$ to $t_{2}$, the anode current decreases according to a constant slope $d I_{F} / d t$. This slope is essentially determined by values of circuit inductors crossed by the current and value of the reverse applied voltage $V_{R}$ across the thyristor. Meanwhile, from $t_{2}$ to $t_{3}$, the anode current increases according to a constant slope $d I_{R} / d t$. For instant $t_{3}$, as mentioned on the current waveform in Fig. 4, the current slope $d I_{R} / d t$ changes suddenly in terms of value, and the current magnitude is about $10 \%$ of the maximum reverse current, $I_{\mathrm{RM}}$, and the space charge region is extended on the maximal position. The remaining amount of charge $Q_{2}$ that includes charges stored in the component gate region is evacuated from instant $t_{3}$ to $t_{4}$. At instant $t_{4}$, the current magnitude through the thyristor is about $1 \%$ of $I_{\mathrm{RM}}$.

In this paper, the developed test circuit has been implemented in DESSIS-ISE TCAD simulator using the mixed-mode simulation. Indeed, a FEM modeling is selected for the thyristor under test. The other components of the test circuit are described by their equivalent circuit models.

The Bennettwilson model [27] and the Philips unified mobility model proposed by Klassen et al. [28] are selected for the effective intrinsic density and the bulk mobility, respectively, in the FEM modeling of the thyristor. Temperature dependence is taken into account for the Shokley-Read-Hall lifetimes [29]. In addition, Auger recombination and the avalanche effects are considered. The temperature dependence of the lattice mobility is implemented as in [30]. The carrier intrinsic concentration follows the well-known temperature dependence, as detailed in [31]. The latter options are suitable for simulation of power semiconductor devices [32]. They are not discussed since these issues are behind the scope of this paper.

An advanced MOS2KP model for "IRF740" MOSFET developed in the literature [33] has been accounted in the test circuit modeling, instead of using the classical SPICE Level-3 model due to its poor accuracy. The switching cell is simulated, taking into account the self-inductances and mutual inductances of the layout, as shown in Fig. 5. An inductance matrix describing the wiring parasitic model of the experimental circuit has been identified using the INCA software [34]. This platform uses the partial element equivalent circuit method [35].

A cable model developed in [36], taking into account the propagating effect, is considered for the connection between the shunt and the oscilloscope during the simulation. To avoid any other types of error sources that can introduce delay and distortions for measured signals, the shunt and probe models described in [36] are also considered in this paper.

\section{Extraction Procedure}

Commercial systems such Integrated Circuit Characterization and Analysis Program (IC-CAP) [37], [38], do not propose

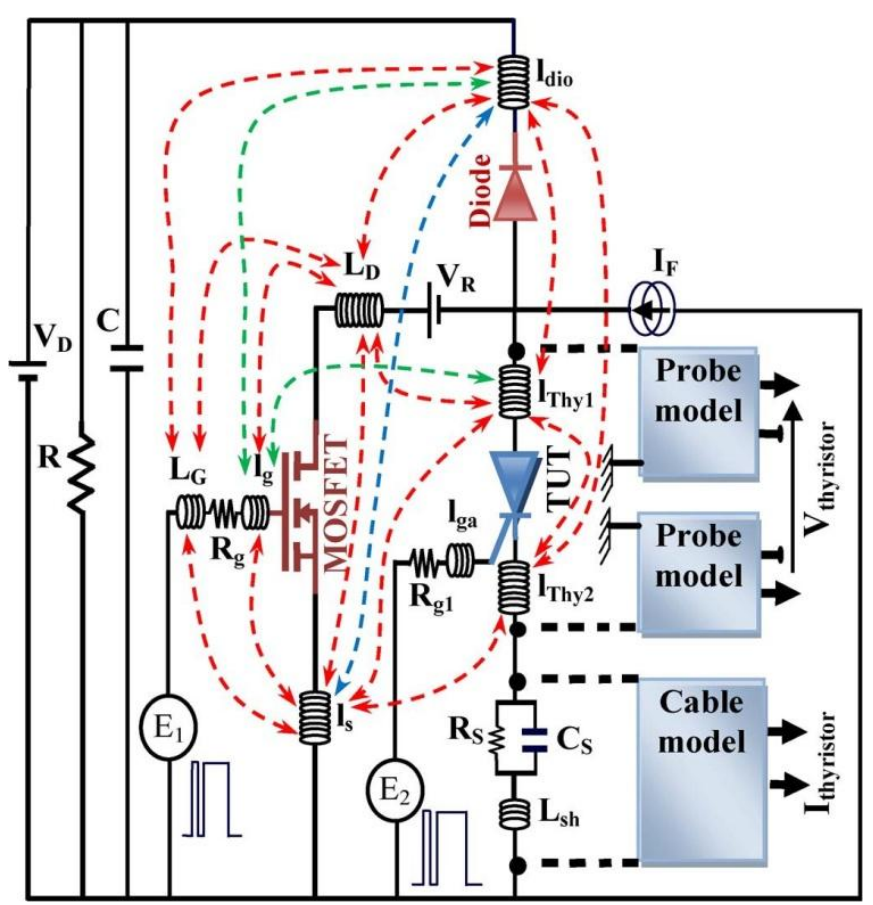

Fig. 5. Circuit model including a par asitic wiring model and probe models.

solutions for the thyristor. Moreover the high-level injection, the dynamic avalanche [39], [40] and the Kirk effect [41] have to be considered. In [42], global optimization algorithms are used to minimize a cost function which is a comparison criterion between measurements and associated simulations during turn-off transient behavior of devices. Since all parameters are coupled together, the proposed technique remains heavy, since it requires hundreds or thousands of simulations and therefore several days of computing time. In this paper, a novel approach based on physics of thyristor component to extract its design parameters is detailed. Indeed, after having characterized some commercial thyristors, an extraction procedure based on a concept of decoupling of their design parameters is described. A step-by-step extraction procedure dedicated for the thyristor device is shown in Fig. 6. The extraction procedure should be performed for thyristor under test, once that an accurate model of the experimental circuit is established.

Step \#1 gives the initial values of the width $W_{B}$ and the doping concentration $N_{B}$ of the thyristor base region and the width $W_{g}$ and the doping concentration $N_{g}$ of its gate region and the effective area $A$. Step \#2 is dedicated to refine the basic parameters $N_{B}$ and $W_{B}$. Step \#3 estimates the value of the ambipolar lifetime in the thyristor base region from current waveform during the component turn-off phase. Step \#4 is devoted to estimate the value of the doping concentration $N_{g}$ and the width $W_{g}$ of the gate region during the device turn-off transient behavior. Step \#5 refines the device effective area.

\section{A. Step \#1: Initialization of $W_{B}, N_{B}, W_{g}, N_{g}$ and $A$}

Device engineers are making tradeoffs to best meet the constraint on breakdown voltages, fast switching, low forward voltages and high forward current densities. 


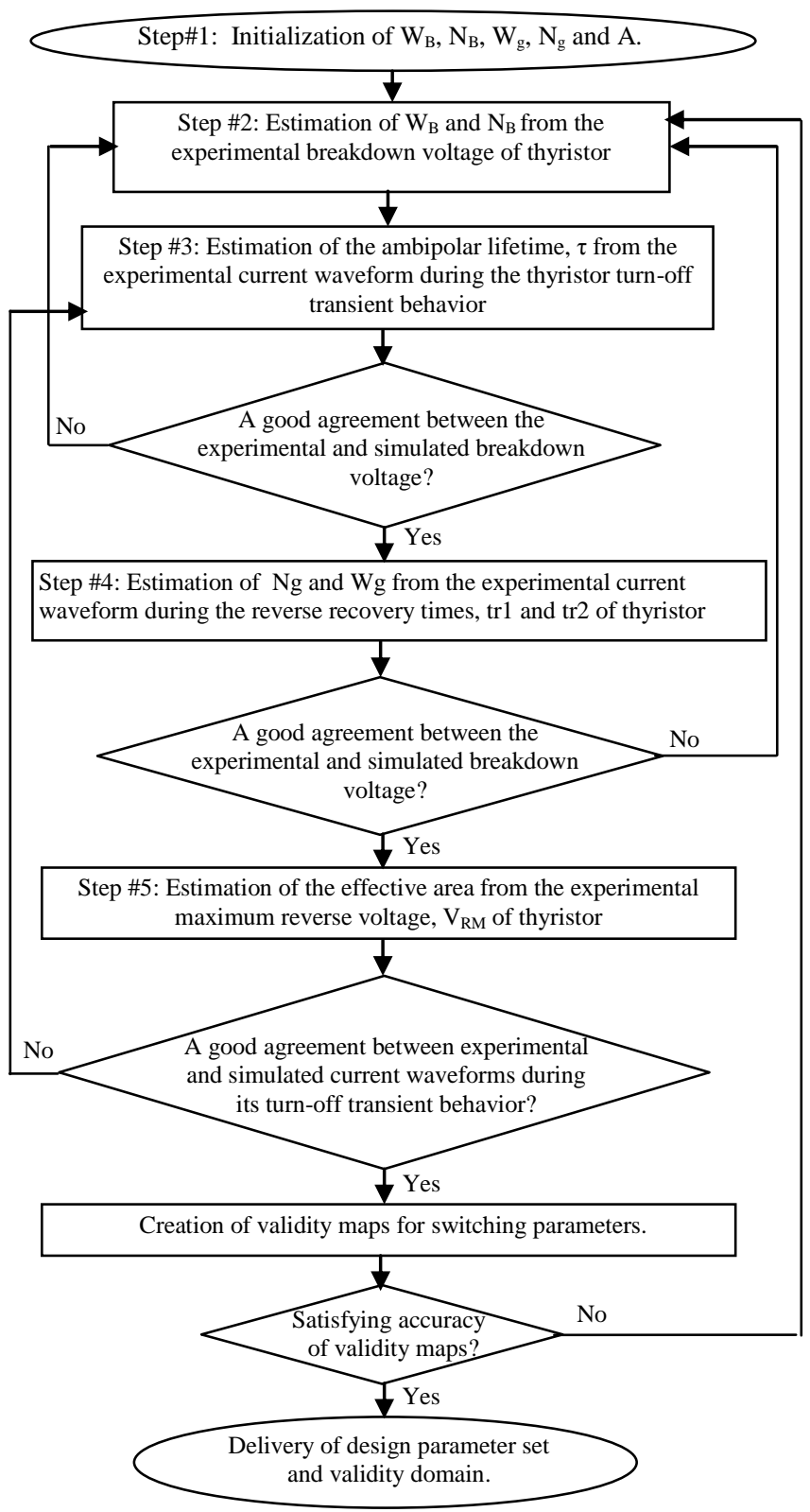

Fig. 6. Extraction procedure algorithm.

The breakdown voltage is related to $N_{B}$ and $W_{B}$ of the lightly doped region of the device [37] where the electric field and the space charge region will extend when the component is reverse biased. The study of edge terminations of thyristors is outside the scope of this paper, and the breakdown voltage is assumed to be mainly determined by the device volume properties. The thyristor model shown in Fig.1 is simulated in the circuit of Fig. 7 (a), for various values of $N_{B}$ and $W_{B}$.

In Fig. 7 (b), it is noted that the device breakdown voltage increases as the doping level of the lightly doped layer decreases and when its thickness increases. To optimize the resistance of the lightly doped layer, a good tradeoff between a low forward voltage drop and a high breakdown voltage should be found. This tradeoff corresponds to a parameter couple ( $W_{B}$ and $N_{B}$ ) located just in the knee region [31], [43], as mentioned in Fig. 7 (b).

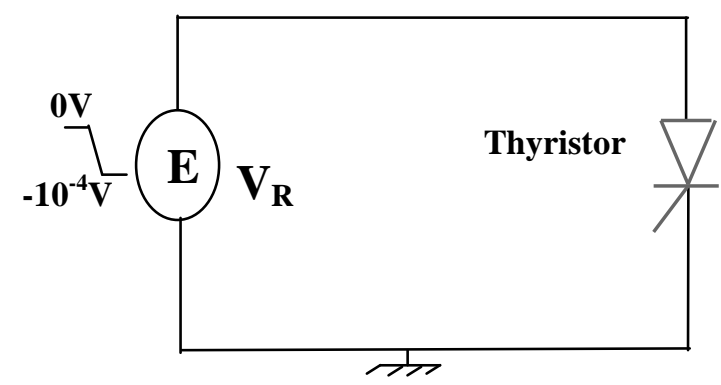

(a)

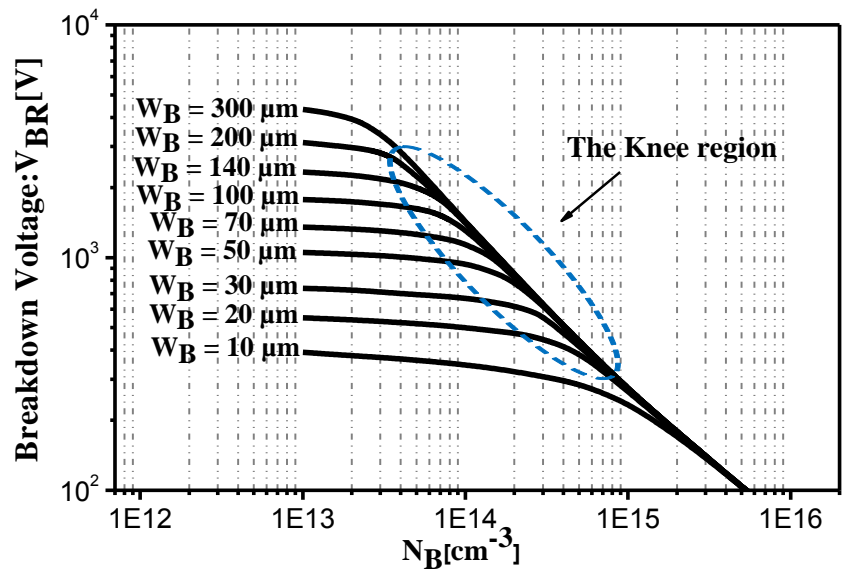

(b)

Fig.7. (a) Simulation circuit for breakdown voltage estimation. (b) Estimation breakdown voltage using simplified 2-D model in Fig.1

For setting the $W_{B}$ and $N_{B}$ parameters, the smallest thickness and the highest doping of the thyristor base region in the knee region are selected. From a visual inspection, initial values of $W_{B}$ and $N_{B}$ are selected. The estimation of the initial value of the effective area of the component can be deduced from the current density usually given by the manufacturer according to the law given by $A_{o p}=I_{F} / J_{N}$, where $J_{N}$ is the typical density of current (from 100 to $300 \mathrm{~A} / \mathrm{cm}^{2}$ ) and $A_{o p}$ is the optimal effective area of the device.

For initialization of parameter values of the thyristor gate layer, $W_{g}$ is set to a smaller value than $W_{B}$ and $N_{g}$ is set to a higher value than $N_{B}$.

\section{B. Step \#2: First Refinement of $W_{B}$ and $N_{B}$}

The refinement of these two parameters is performed by matching experimental and simulated reverse static characteristics. Using a Tektronix 371A high-power curve tracer, experimental $I-V$ curves of thyristors under test are acquired. The simulation results are obtained through numerical simulation using DESSIS-ISE TCAD simulator in quasi-stationary mode. After having initiated a series of simulation by varying the $W_{B}$ and $N_{B}$ parameter values, a good agreement is obtained between the experimental and simulated waveforms of the breakdown voltages of three commercial thyristors $2 \mathrm{~N} 6508 \mathrm{G}, 2 \mathrm{~N} 6397 \mathrm{G}$ and BT153 as illustrated in Fig. 8(b). The estimated parameters for each component are given in Fig. 8(a). 


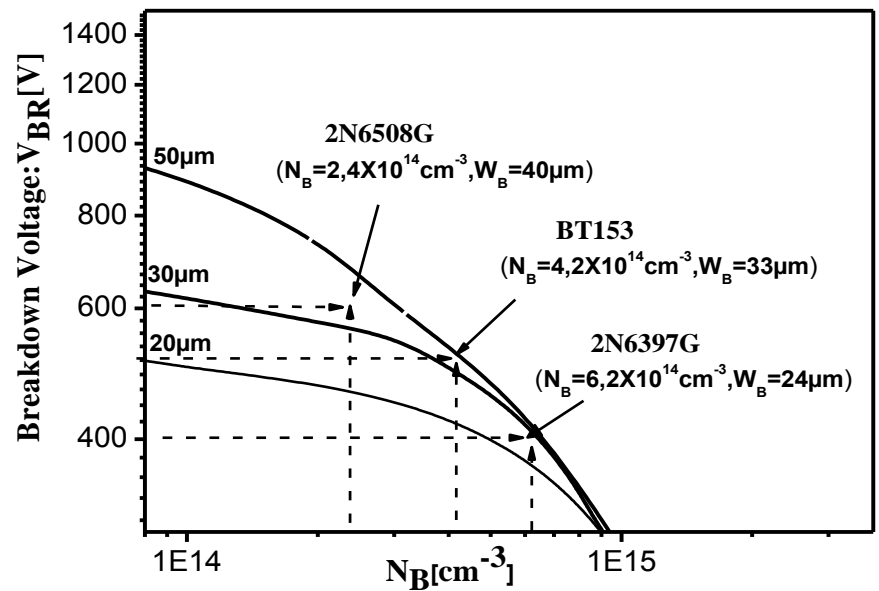

(a)

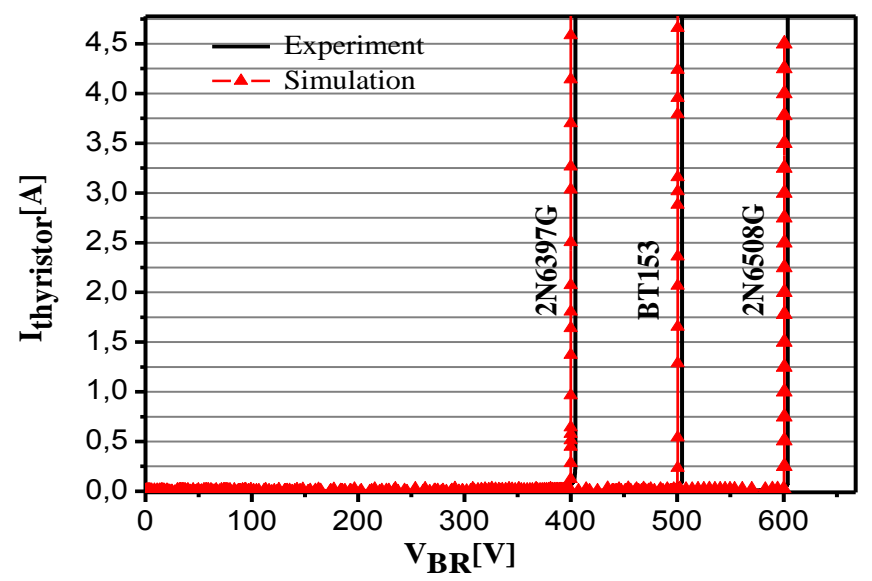

(b)

Fig.8 . Refinement of $W_{B}$ and $N_{B}$ based on reverse-bias I-V curve. (a) Refined values of $W_{B}$ and $N_{B}$. (b) Simulated and experimental breakdown voltage for three commercial devices.

\section{Step \#3: Estimation of $\tau$ and refinement of $W_{B}$ and $N_{B}$}

First, the ambipolar lifetime is a fundamental parameter for industry of power semiconductor devices. This parameter significantly affects the direct and transient behavior of power devices and, in particular, their switching speed. Device design engineering creates deep recombination centers by instance by diffusion of heavy metals ( $\mathrm{Au}$ or $\mathrm{Pt}$ ) in the lightly doped region, to optimize and to control the ambipolar lifetime [44]. During turn-off transient behavior of the thyristor, stored charge in the lightly doped region, while the component is turned on, is evacuated. This amount of stored charge in the base and gate regions is related to the ambipolar lifetime. Several simulations are performed to predict the influence of the ambipolar lifetime variation on current and voltage waveforms during the thyristor turn-off switching. It is noted that the switching parameters $I_{\mathrm{RM}}$ and the reverse recovery time $t_{\mathrm{rr}}$ and, in particular, the first reverse recovery time $t_{r} 1$ are very sensitive to change of the ambipolar lifetime. Hence, by varying the ambipolar lifetime value, its estimation is obtained by matching simulated and experimental current waveforms, during turn-off transient behavior of the thyristor, and using the DESSIS-ISE TCAD simulator. For this estimated parameter, practically the same value of reverse current, $I_{R M}$ and reverse recovery time, $t_{r 1}$ is obtained for simulated and experimental current waveforms.
Since they are also related to the stored charge during the component turn-on state, $N_{B}$ and $W_{B}$ should be adjusted again. Step\#2 is repeated for the sake of coherence with the latest parameter estimated of $\tau$ and the breakdown voltage of the component is respected.

\section{Step \#4: Estimation of $W_{g}$ and $N_{g}$ of the gate region}

Several simulations using the DESSIS-ISE TCAD simulator are performed to observe the influence of width of the gate region $W_{g}$ and its doping concentration $N_{g}$ on current and voltage waveforms during the thyristor turn-off phase. Influence of these two parameters occurs during the second phase of evacuation of the remaining amount of stored charge in the thyristor gate region. A change of $N_{g}$ value has a remarkable influence first on the second recovery time $t_{\mathrm{r} 2}$ and second on the current magnitude through the thyristor at instant $t_{3}$, as mentioned in Fig. 4. However, a variation of $W_{g}$ affects the reverse recovery time $t_{\mathrm{r} 2}$, while keeping practically the same current amplitude for the instant $t_{3}$. The estimation of the value of doping concentration $N_{g}$ is obtained by matching the simulated and experimental value of the anode current magnitude at instant $t_{3}$. Afterward, $W_{g}$ is varied until matching the experimental and simulated value of $t_{2}$. For these later estimated parameters $W_{g}$ and $N_{g}$, a good agreement is found between experimental and simulated current waveforms during the thyristor turn-off transient behavior. For this later estimated doping concentration $N_{g}$, the anode current magnitude for instant $t_{3}$ corresponds practically to $10 \%$ of $I_{\mathrm{RM}}$. The $N_{B}$ and $W_{B}$ settings must be adjusted again, since they are related to the stored charge. Step \#2 should be started again to have a good agreement between the simulated and experimental current waveforms and the same breakdown voltage of the thyristor under test in simulation and experiment. Step \#3 should be also repeated by the way since the ambipolar lifetime is also related to the stored charge.

\section{E. Step \#5: Estimation of the effective area, A}

At the end of the thyristor reverse recovery, the turn-off experimental voltage waveform presents oscillations due to interactions between the silicon-controlled rectifier extended across anode-base and cathode-gate junctions and the external circuit. During the recovery process, the variation of the device effective area has, therefore, a great effect, particularly on the magnitude of the first oscillation of the voltage waveform, corresponding to the maximum reverse voltage $V_{\mathrm{RM}}$. Thus, estimation of the thyristor effective area $A$ is obtained by matching the simulated and experimental value of $\mathrm{V}_{\mathrm{RM}}$. This latter estimated value of $A$ corresponds to a good agreement between simulated and experimental voltage waveforms across the component during its turn-off switching. Since the stored charge inside the lightly doped region of the thyristor, when it is turned on, is also related to its effective area, the optimization of the ambipolar lifetime procedure must be restarted again with the estimated value of the effective area. Therefore, the optimization step of $N_{B}$ and $W_{B}$ values must be performed again to 
TABLE III.

COMPARISON OF SWITCHING PARAMETER VALUES FOR A 2N6508G THYRISTOR

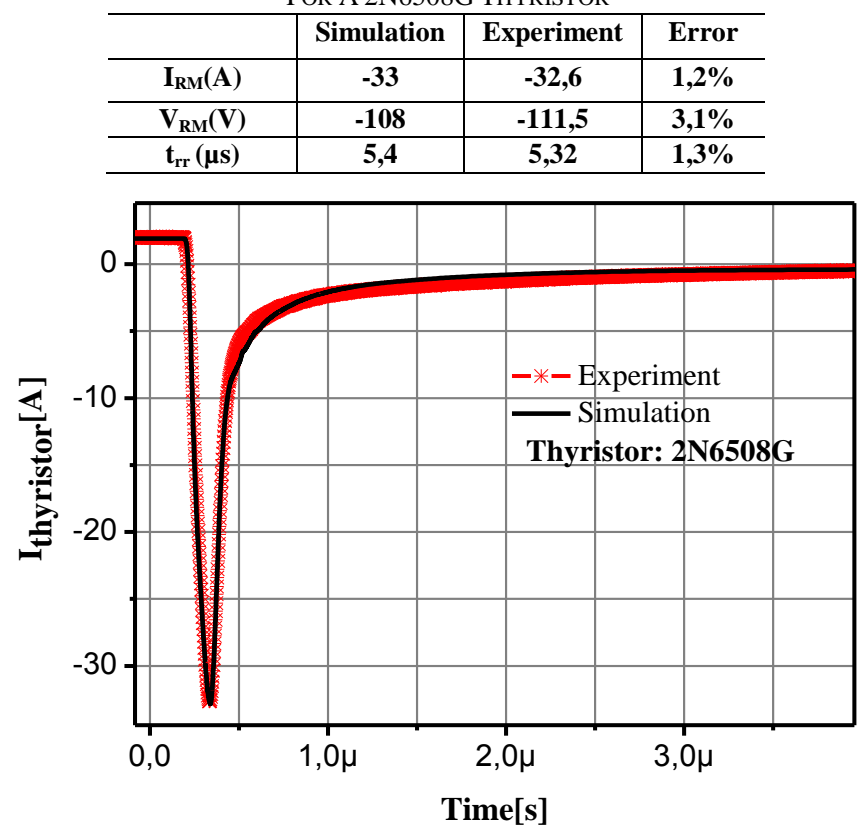

(a)

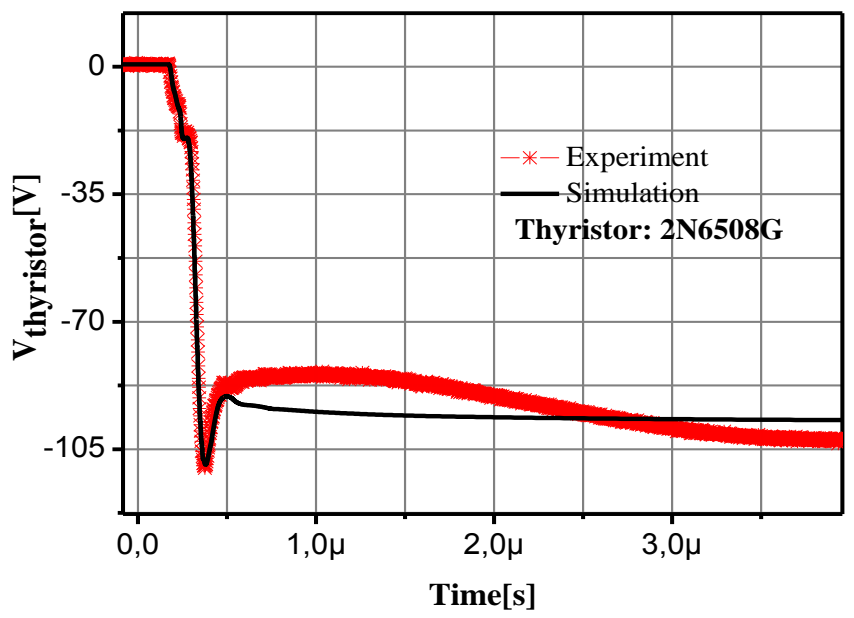

(b)

Fig. 9. Comparison of experimental and simulation results. (a) Current waveforms. (b) Voltage waveforms.

respect the measured breakdown voltage of the thyristor under test. Steps \#2 and \#3 are also repeated.

The step-by-step extraction procedure is adopted and performed for three commercial thyristors under test. Table III reports the experimental and simulated values of the main switching parameters $I_{R M}, V_{R M}$, and $t_{r r}$ of the $2 \mathrm{~N} 6508 \mathrm{G}$ thyristor for the following operation conditions: $\mathrm{I}_{\mathrm{F}}=2 \mathrm{~A}$ and $\mathrm{V}_{\mathrm{R}}=100 \mathrm{~V}$.

A good agreement is observed between experimental and simulated waveforms, as shown in Fig. 9. This agreement is slightly degraded after the high $d v / d t$ and before steady state. Indeed, some oscillations appear in the experimental voltage waveform during this slot time. This disagreement may be due to inaccuracy in the representation of inductive and capacitive parasitic elements and inaccuracy of the component geometry. The 3-D effect not supported in our work for the FEM modeling of the thyristor could be also a cause of this disagreement. This
TABLE IV.

OPTIMAL DESIGN PARAMETER SET

FOR THREE COMMERCIAL THYRISTORS

\begin{tabular}{c|c|c|c}
\hline Thyristor & 2N6508G & 2N6397G & BT153 \\
\hline $\mathbf{N}_{\mathrm{B}}\left(\mathbf{c m}^{-3}\right)$ & $2,3.10^{14}$ & $6.10^{14}$ & $4.10^{14}$ \\
\hline $\mathrm{W}_{\mathrm{B}}(\mu \mathrm{m})$ & 41 & 23 & 32 \\
\hline $\mathrm{N}_{\mathrm{g}}\left(\mathrm{cm}^{-3}\right)$ & $1,95.10^{17}$ & $1,15.10^{17}$ & $\mathbf{1 , 4 . 1 0}^{17}$ \\
\hline $\mathrm{W}_{\mathrm{g}}(\mu \mathrm{m})$ & 4,2 & 6 & 5 \\
\hline $\mathrm{A}\left(\mathbf{m m}^{2}\right)$ & 35 & 28 & 33,6 \\
\hline$\tau(\mu \mathrm{s})$ & 9 & 5 & 8 \\
\hline
\end{tabular}

disagreement has no important effects on the extracted design parameters.

Extracted design parameters for three commercial thyristors under test are shown in Table IV.

To additionally validate the extracted effective area of the thyristor under test, its current density $J=I_{N} / A$ is computed, where $I_{N}$ is its nominal current, and $A$ is its effective area. For example, for the $2 \mathrm{~N} 6397 \mathrm{G}$ thyristor, $J=$ $5 \mathrm{~A} / 28 \mathrm{~mm}^{2}=178.6 \mathrm{~A} / \mathrm{cm}^{2}$. This value is in good agreement with the typical value mentioned previously $\left(100 \mathrm{~A} / \mathrm{cm}^{2}<\right.$ $J_{N}<300 \mathrm{~A} / \mathrm{cm}^{2}$ ). Therefore, the effective area of the component fits well with its physical size.

\section{VALIDITY DOMAIN}

The validity of extracted design parameters of the thyristor under test is examined by an electrothermal simulation study. Indeed, a comparative study is performed between experimental and simulated waveforms of current and voltage across the device 2 N6397G for high operating temperatures. Inside the switching cell circuit, the thyristor operating temperature is controlled by an air flow using a thermal stream system model TP041AH, where the temperature is monitored by a thermocouple and controlled by a microprocessor that regulates the air stream temperature with high stability and accuracy. Fig. 10 pictures experimental current and voltage waveforms for various operating temperatures. From this figure, it is noted that the switching parameters $I_{\mathrm{RM}}$ and $t_{\mathrm{rr}}$ increase with the thyristor operating temperature, while $V_{\mathrm{RM}}$ decreases with $T_{\mathrm{O}}$. To compare these experimental data to simulation results, the electrothermal simulation mode is selected for thyristor modeling using the DESSIS-ISE TCAD simulator, taking into account their extracted design parameters. An excellent agreement is obtained between experimental and simulated current and voltage waveforms for various operating temperatures during the thyristor turn-off transient behavior, as shown in Fig. 10 .

The extracted design parameters of 2N6397G, 2N6508G, and BT153 devices shown in Table II are used in the electrothermal simulation. To compare the experimental data to simulation results for these three commercial thyristors, the simulated and experimental values of the main switching parameters are selected to be compared since they characterize the turn-off waveforms. Fig. 11 compares several simulation and experimental results about the main switching parameters for the three commercial thyristors. A good agreement is found between simulated and experimental results since error between them is less than $2 \%$. 


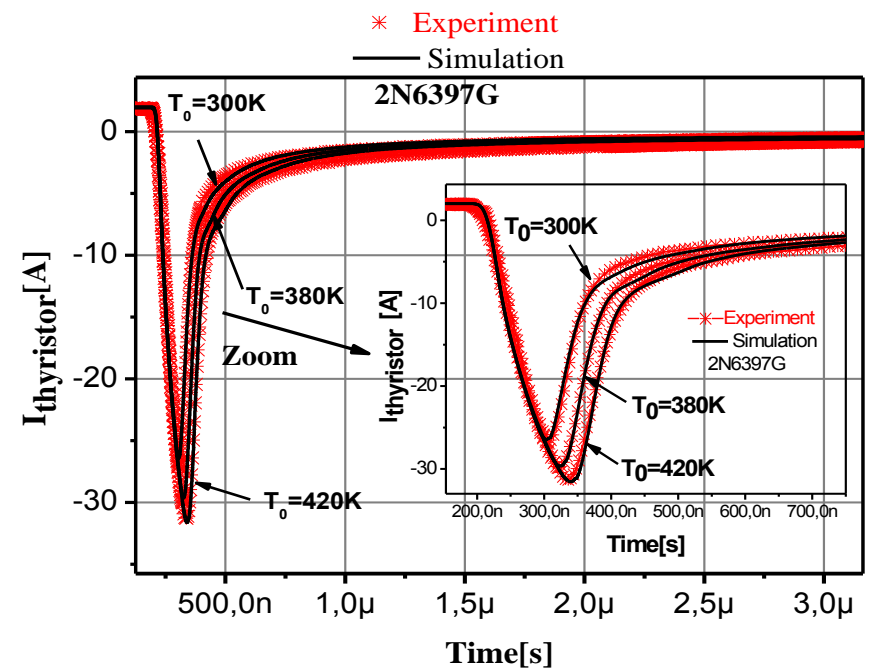

(a)

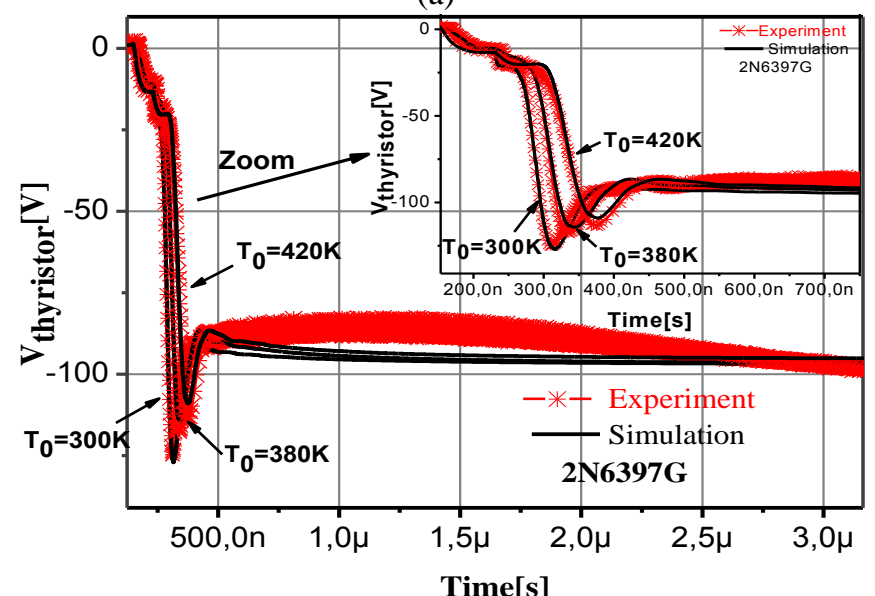

(b)

Fig. 10. Comparison of experimental and simulation results at various operating temperatures. (a) Current waveforms. (b) Voltage waveforms.

All extracted design parameters of various thyristors under test are mainly deduced from current and voltage waveforms across components during their turn-off transient behavior for operating conditions $\left(I_{F}=2 \mathrm{~A}\right.$ and $\left.V_{R}=100 \mathrm{~V}\right)$. To further highlight validity of extracted design parameters, a comparative study between experimental and simulated switching parameter values versus $I_{F}$ current and $V_{R}$ voltage should be established. The error evolution between simulated and experimental value of $t_{r r}, V_{R M}$ and $I_{R M}$ parameters versus $I_{F}$ current and $V_{R}$ voltage are dressed in maps on Fig. 12.

Thereby the validity maps of thyristor model including extracted parameters could be discussed. An error less than $6.8 \%$ is observed in the $\mathrm{V}_{\mathrm{RM}}$ validity map. However $\mathrm{t}_{\mathrm{rr}}$ and $\mathrm{I}_{\mathrm{RM}}$ validity maps indicate an error less than $4.8 \%$.

Validity maps of $\mathrm{V}_{\mathrm{RM}}, \mathrm{I}_{\mathrm{RM}}$ and $\mathrm{t}_{\mathrm{rr}}$ demonstrates the validity of the extraction procedure and the extracted design parameters of thyristor under test since the error rate between simulated and experimental values of switching parameters remain acceptable. Some perturbations of measurement are found for high current, $I_{F}$ and for high voltage $V_{R}$. These perturbations constitutes the technical limitations of the work bench which explain why the $I_{F}$ current and the $V_{R}$ voltage did not exceed respectively $5 \mathrm{~A}$ and $200 \mathrm{~V}$ in the validity maps. These technical limitations do not prevent the extraction of the thyristor design parameters.

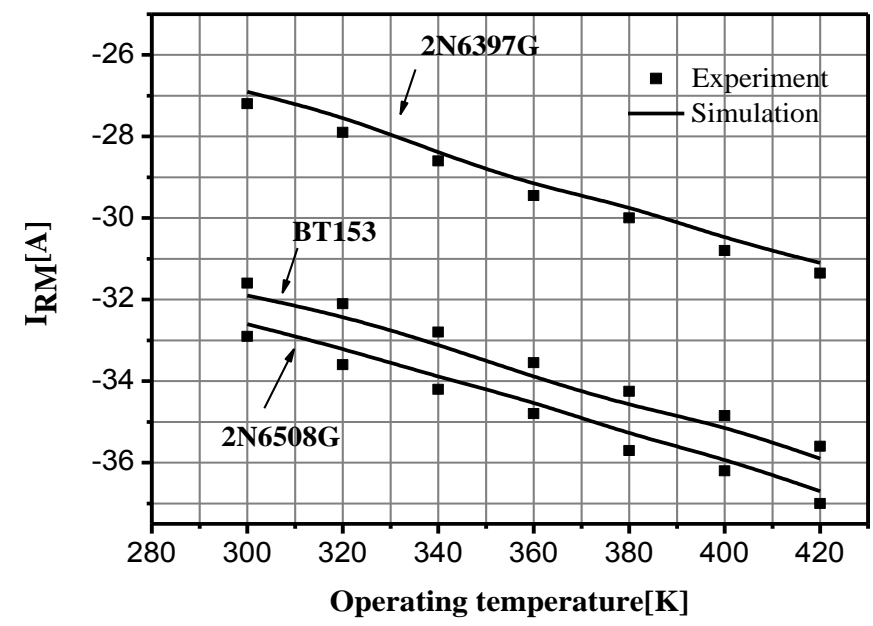

(a)

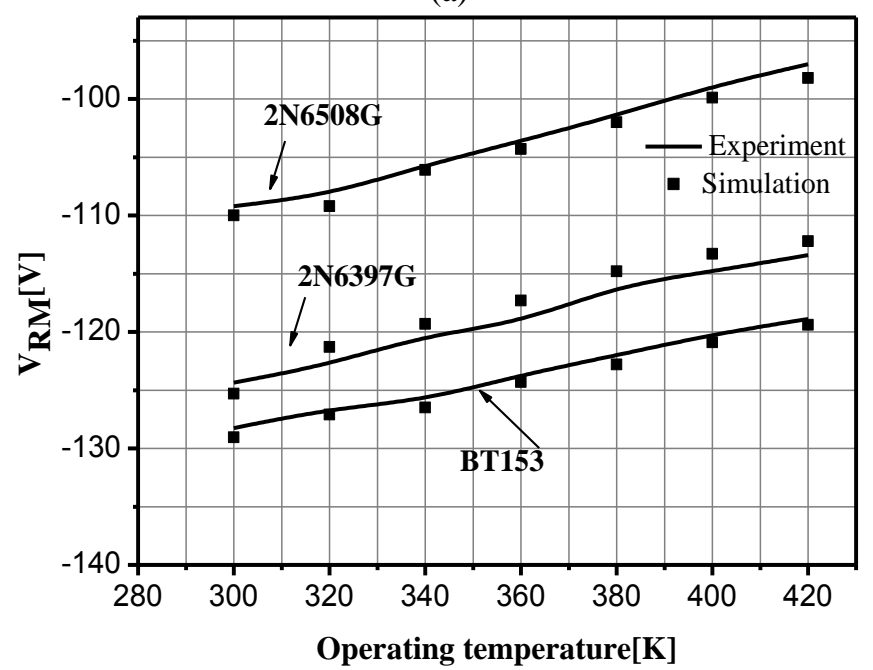

(b)

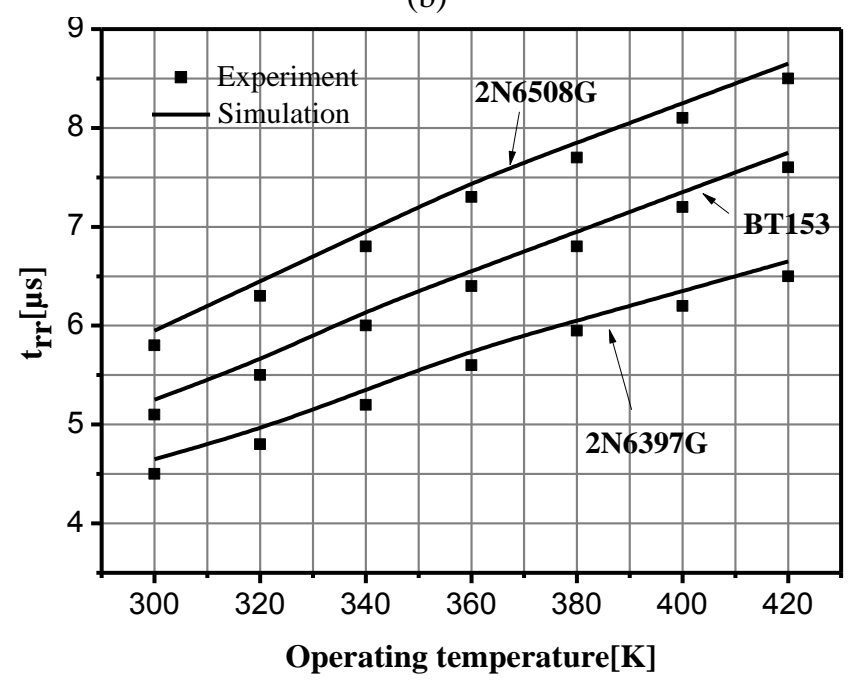

(c)

Fig. 11. Experimental and simulated of main switching parameters versus the operating temperature for three commercial thyristors: (a) $\mathrm{I}_{\mathrm{RM}}$, (b) $\mathrm{V}_{\mathrm{RM}}$ and (c) $\mathrm{t}_{\mathrm{rr}}$.

\section{CONCLUSION}

We have shown that it is possible to accurately extract the main design parameters of thyristor, using a novel approach based on concept of decoupling of their design parameters, taking into account the physics of the component. On the one 


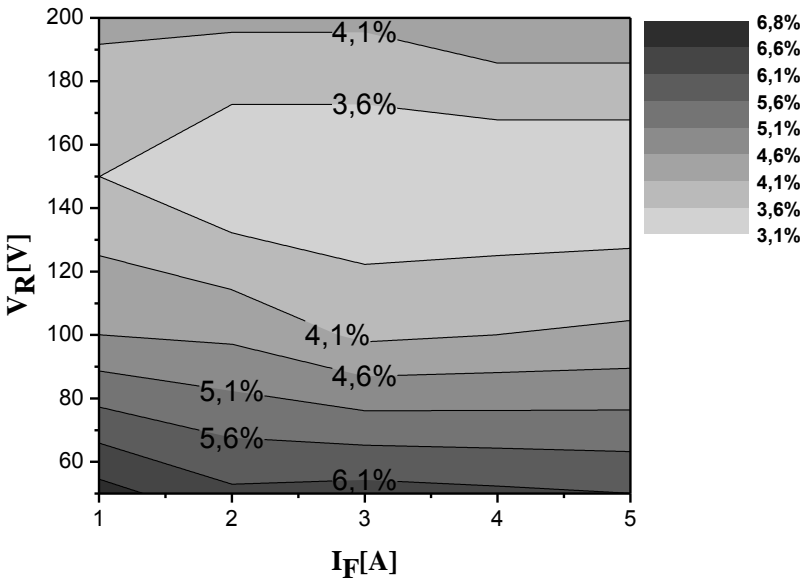

(a)
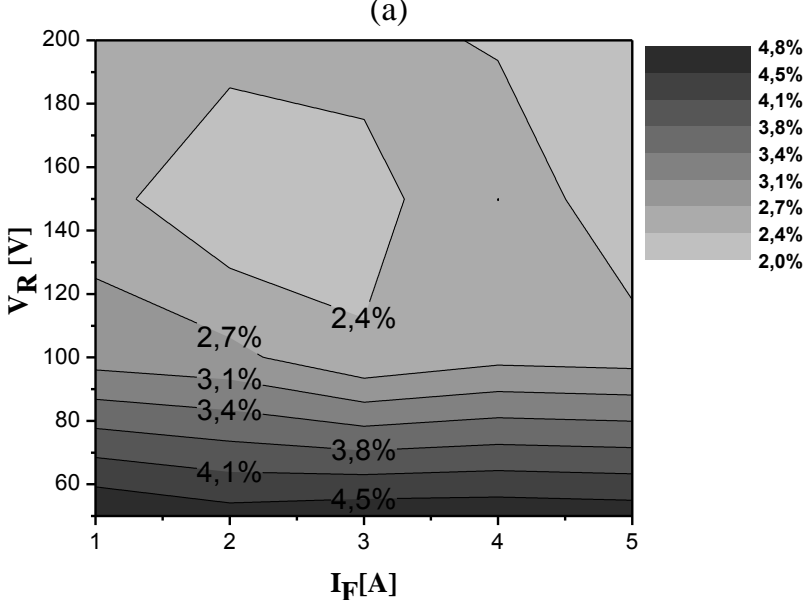

(b)

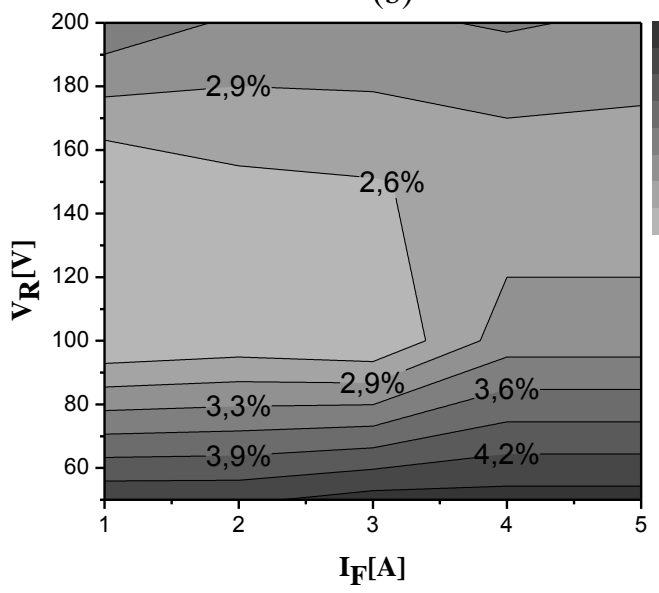

(c)

Fig. 12. Validity maps of switching parameters for the device 2N6508G. (a) $\mathrm{V}_{\mathrm{RM}}$, (b) $\mathrm{t}_{\mathrm{rr}}$ and (c) $\mathrm{I}_{\mathrm{RM}}$.

a sophisticated switching cell circuit is required to acquire measurements. One the other hand, the simulation requires an accurate model of the switching cell wiring and models for the current and voltage probes. A step-by-step extraction procedure of thyristor design parameters is developed and appears as a 5-step procedure repeated until satisfying accuracy. The design parameters of three commercial thyristors are extracted. To evaluate the efficiency of the extraction procedure, an electro-thermal study of these thyristors is performed and excellent agreements between experimental and simulated results are obtained.
Although a simplified 2-D thyristor design model has been considered, excellent results have been detected in the validity range of the estimated parameters. This extraction procedure of thyristor design parameters appears also very fast since it is not expensive from the CPU-cost point-of-view. It only requires few loops. Finally, such results show that it is possible to perform very accurate simulations of a complete circuit using FEM simulations. This is a starting point for developing accurate analytical models of thyristor, which will be useful in CAD of power electronic systems including thyristors even GTO. Moreover the paper should serve as a reference for the extraction procedure even for future analytical models. The methodology of the developed extraction procedure is dedicated to silicon and silicon carbide thyristor. The next step will be to apply the extraction procedure to SiC-thyristors.

\section{REFERENCES}

[1] B. Bose, "Power electronics and motor drives: Recent progress and perspective," IEEE Trans. Ind. Electron., vol. 56, no. 2, pp. 581-588, Feb. 2009.

[2] E. C. Nho, B. M. Han, Y. H. Chung, S. T. Baek and J. H. Jung, "Synthetic Test Circuit for Thyristor Valve in HVDC Converter with New High-Current Source," IEEE Trans. Power Electron., vol. 29, no. 7, pp. 3290-3296, Jul. 2014.

[3] V. Guerrero, J. Pontt, J. Dixon and J. Rebolledo, "A Novel Noninvasive Failure-Detection System for High-Power Converters Based on SCRs," IEEE Trans. Ind. Electron., vol. 60, no. 2, pp. 450-458, Feb. 2013.

[4] A. Tessarolo, C. Bassi, G. Ferrari, D. Giulivo, R. Macuglia, and R. Menis, "Investigation Into the High-Frequency Limits and Performance of Load Commutated Inverters for High-Speed Synchronous Motor Drives," IEEE Trans. Ind. Electron., vol. 60, no. 6, pp. 2147-2157, Jun. 2013.

[5] S. Srdic, and M. Nedeljkovic, "Predictive Fast DSP-Based Current Controller for Thyristor Converters," IEEE Trans. Ind. Electron., vol. 58, no. 8, pp. 3349-3358, Aug. 2011.

[6] B. Wu, J. Pontt, J. Rodríguez, S. Bernet and S. Kouro, "Current-Source Converter and Cycloconverter Topologies for Industrial MediumVoltage Drives," IEEE Trans. Ind. Electron., vol. 55, no. 7, pp. 27862797, Jul. 2008.

[7] S. L. Rumyantsev, M. E. Levinshtein, M. S. Shur, L. Cheng, A. K. Agarwal, 4 and J. W. Palmour, "Optical Triggering of High-Voltage (18 kV-class) 4H-SiC Thyristors," Semicond. Sci. Technol., vol 28, no. 12, (4p), Nov. 2013.

[8] S. Bayne, S. Lacouture, K. Lawson, M. Giesselmann, C. J. Scozzie, H. O'Brien and A. Ogunniyi, "An evaluation system for experimental silicon and silicon carbide super gate turn off thyristors," Rev. Sci. Instrum., vol. 85, no. 7, pp. 075107- 075107-5, 2014.

[9] K. Lawson, S. Bayne, S. Lacouture, L. Cheng, H. O'Brien, A. Ogunniyi, and C. Scozzie, "Safe Operating Area and Long-Term Reliability of 9-kV Silicon Carbide PNPN Super Gate Turn-Off Thyristors," IEEE Electron Device Lett., vol.35, no. 8, pp. 862-864, Aug. 2014.

[10] H. Garrab, B. Allard, H. Morel, K. Ammous, S. Ghedira, A. Ammimi, K. Besbes and J.M Guichon, "On the extraction of PIN diode design parameters for validation of integrated power converter design," IEEE Trans. Power Electron., vol. 20, no. 3, pp. 660-670, May. 2005.

[11] T. Ben salah, S. Ghedira, H. Garrab, H. Morel, D. Risaletto, K. Besbes. "A novel approach to extract accurate design parameters of PiN diode," Inter. Jour. Num. Model. Electron. Netw. Dev. And Fields., vol. 20, no. 6, pp. 283-297, Apr. 2007.

[12] R. Fu, A. Grekov, K. Peng and E. Santi, "Parameter Extraction Procedure for a Physics-based Power SiC Schottky Diode Model," IEEE Trans. Ind. Appl., vol. PP, no. 99, pp. 862-864, Feb. 2014.

[13] R.Chibante, A Araujo, A Carvalho, "Finite-Element Modeling and Optimization-Based Parameter Extraction Algorithme for NPT-IGBT," IEEE Trans. Power Electron., vol. 24, no. 5, pp. 1417-1427, May. 2009.

[14] A.E. Grekov, Zhiyang Chen, Ruiyun Fu, J.L.Hudgins, H.A.Mantooth, D.C.Sheridan, J.Casady, E. Santi, "Parameter Extraction Procedure for 
Vertical SiC Power JFET," IEEE Trans. Ind. Appl., vol. 47, no. 4, pp. 1862 - 1871, Jul./Aug. 2011.

[15] S. Fregonese, S. Lehmann, T. Zimmer, M. Schroter, D. Celi, B. Ardouin, H. Beckrich, P. Brenner, W. Kraus, "A computationally efficient physics-based compact bipolar transistor model for circuit Design-part II: parameter extraction and experimental results," IEEE Trans. Electron Devices., vol. 53, no. 2, pp. 287-295, Feb. 2006.

[16] A. A. Zekry, G. T. Sayah, F. A. Soliman, "SPICE model of thyristors with amplifying gate and emitter-shorts," IET. Power Electron., vol. 7, no. 3, pp. $724-735$, Mar. 2014.

[17] B. Chen, X. Zhou and A. Q. Huang, "Physics-based Model for Emitter Turn-Off Thyristor (ETO)," in Proc. IEEE Power Electronics Specialists Conf., 2007, pp. 1930 - 1934.

[18] C. L. Ma, P. O. Lauritzen, and J. Sigg, "Modeling of High Power Thyristors Using the Lumped-charge Modeling Technique," in Proc. EPE Conf., vol. 2, Sept. 1995. pp. 2015-2020.

[19] C. L. Ma, P. O. Lauritzen, and J. Sigg, "A Physics-based GTO Model for Circuit Simulation," in Proc. IEEE Power Electronics Specialists Conf., vol. 2, 1995, pp. $872-878$.

[20] O. S. Saadeh, H. A. Mantooth, J. C. Balda, A. K. Agarwal, A. S. Kashyap, "The Modeling and Characterization of Silicon Carbide Thyristors," in Proc. IEEE Power Electronics Specialists Conf., 2008, pp. $1092-1097$.

[21] S. Bellone, G. Persiano, and A. Strollo, "A measurment method of the injection dependence of the conductivity mobility in silicon," IEEE Electron Device Lett., vol. 16, no. 3, pp. 91-93, Mar. 1995.

[22] MDRAW-ISE TCAD Release 10.0: User's Guide Manual, Integrated Systems Engineering, Zurich, Switzerland. (2004).

[23] DESSIS-ISE TCAD Release 10.0: User's Guide Manual, Integrated Systems Engineering, Zurich, Switzerland. (2004).

[24] Products Series SDN-414, T\&M Research. (2013). [Online]. Available: http://www.tandmresearch.com

[25] P5100 Voltage Probe: Data Sheet, Tektronics. (2013). [Online]. Available : http ://www.tek.com

[26] E.I. Carroll, R.S. Chokawali, Rj. Huard, "Accurate measurement of Energy Loss in Power Semi-conductors," in Proc. Eur. Inter. Intelligent Motion Conf. (PCIM'90), May. 1990.

[27] M.A. Green, "Intrinsic concentration, effective density of state and effective mass in silicon," Jour. Appl. physics., vol. 67, no. 6, pp. 29442954, Mar. 1990.

[28] D.B.M Klassen, J.W Slotboom, H.C. Graaf, "Unified apparent band gap narrowing in $\mathrm{n}$ and $\mathrm{p}$ type silicon," Solid-state Electronics., vol. 35, no. 2, pp. 125-129, 1992.

[29] M.S. Tyagi, R. van Overstraeten, "Minority carrier recombination in heavily-doped silicon," Solid-state Electronics., vol. 26, no. 6, pp. 577597, 1983.

[30] C. Lombardi, S. Manzini, S. Saporito, M. Vanzi, "A physically based mobility model for numerical simulation of non planar devices," IEEE Trans. CAD., vol. 7, no. 11, pp. 1164-1171, Nov. 1988.

[31] S. Sze, Physics of Semiconductor Devices, 3rd ed. New York: Wiley, 2001

[32] G. Wachutka, "An extended thermodynamic model for the simultaneous simulation of the thermal and electrical behavior of semiconductor devices," in Proc. Int. NASECODE Conf., 1989, pp. 409 - 414.

[33] Hatem Garrab, " Contribution à la modélisation électro-thermique de la cellule de commutation MOSFET-Diode", Ph.D. dissertation, INSA de Lyon, France, 2003. [online]. Available : http://theses.insalyon.fr/publication/2003ISAL0009/these.pdf

[34] O. Muhlfeld, F. W. Fuchs, "Comprehensive Optimization Method for Thermal Properties and Parasitics in Power Modules," in Proc. IEEE Energy Conversion Congress and Exposition., 2010. pp. 2266 - 2271

[35] O. Muhlfeld, F.W. Fuchs, "Optimization of the Stray Inductance in Three-Phase MOSFET Power Modules Aided by means of PEEC Simulation," in Proc. EPE Conf., 2009, pp. 1-7.

[36] K. Ammous, H. Morel, A. Ammous, "Analysis Of Power Switching Losses Accounting Probe Modeling," IEEE Trans. Instrumentation and Measurement., vol. 59, no. 12, pp. 3218 - 3226, Dec. 2010.

[37] Agilent technologies, IC-CAP Device modeling software, Complete and Accurate Parameter Extraction for semiconductor Device modeling, Technical overview (2012). [Online].Available: http://www.Keysight.com

[38] G. Darbandy, T. Gneiting, H. Alius, J. Alvarado, A. Cerdeira and B. Iñiguez, "Automatic Parameter Extraction Techniques in IC-CAP for a Compact Double Gate MOSFET Model," Semicond. Sci. Technol., vol. 28, no. 5, (8p), May. 2013.
[39] M. Domeij, J. Lutz, D. Silber, "On the destruction limit of Si power diodes during reverse recovery with dynamic avalanche," IEEE Trans. Electron Devices., vol. 50, no. 2, pp. 486 - 493, Feb. 2003.

[40] J. Lutz, "Fast recovery diodes-Reverse recovery behavior and dynamic avalanche," in Proc. Int. Microelectronics Conf., vol. 1, 2004, pp. 1116.

[41] J. Karamarkovic, T. Pesic, and N. Jankovic, "An analytical approach to kirk effect modeling," in Proc. Int. Semiconducteur Conf., vol. 1, 2000, pp. $311-314$

[42] L.C. Chieh, "Contribution à l'identification des paramètres technologiques de la diode PIN de puissance à partir des caractéristiques de commutations à l'ouverture" Ph.D. Dissertation, INSA de Lyon, France, 1994

[43] B.J.Baliga, Modern power Devices, 2nd ed. Malabar, FL: Krieger, 1995.

[44] H. Banda and E. Spenke, "Reverse recovery processes in silicon power rectifiers," in Proc. IEEE., vol. 55, no. 8, 1967, pp. 1331 - 1354.

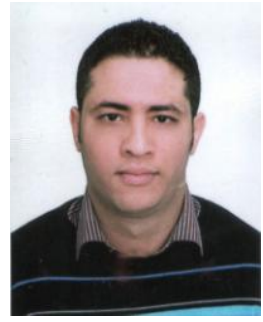

Atef Jedidi was born in Mulhouse, France, on juillet 11, 1980. He received the M.S. and the Master degrees from the Faculty of Sciences of Monastir, Monastir, Tunisia, in 2006 and 2008, respectively. His current research interests are characterization and modeling of power semiconductor devices and the electrothermal modelization.

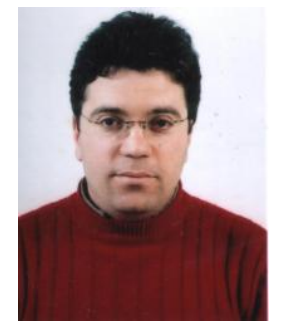

Hatem Garrab (M'13) was born in Jemmel, Tunisia, on Avril 05, 1973. He received the M.S. and the Diplome des Etudes Approfondies (DEA) degrees from the Faculty of Sciences of Monastir, Monastir, Tunisia, in 1995 and 1997, respectively, and the Ph.D. degree from the Institut National des Sciences Appliquées (INSA), Lyon, France, in 2003.

In 2003, he joined the University of Sousse as an assistant Professor in Electronics and microelectronics in the Institut Supérieur des Sciences Appliquées et de technologies de Sousse, Sousse, Tunisia. His research interests include power semiconductor device modeling and characterization and multi-physics modeling based on bond graphs.

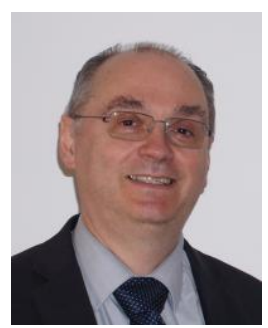

Hervé Morel (M'00-SM'07) was born in Reims, France in 1959. He received the Engineer and $\mathrm{PhD}$ degrees from Ecole Centrale de Lyon in 1982 and 1984 respectively.

In 1985, he joined the CNRS as Associated Scientist. He is currently a CNRS Senior Scientist at the INSA Lyon, Ampere Lab. From 2012 to 2014, he was a program officer at the ANR, the French research founding agency (Renewable generation and management of electricity). He published more than 90 articles in referred journals.

His research area includes power semiconductor device characterization and modeling, CAE of Power Electronic System Integration, multi-physics modeling based on bond graphs. He is particularly involves in the design of high temperature power electronics for the More Electric Aircraft, and high voltage power electronics for the electric grids. 


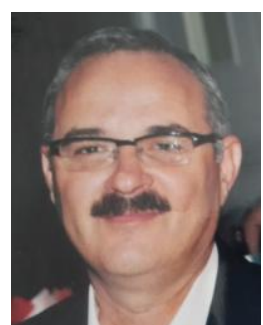

Kamel Besbes (M'13) born in 1960 in Monastir, Tunisia, received M.S. degree from the Ecole Centrale de Lyon-France in 1986, the $\mathrm{PhD}$ degree from INSA Lyon, France in 1989 and the "State Doctorate Degree" from the Faculty of Sciences of Tunis-Tunisia in 1995.

In 1989, he joined the University of Monastir. He established teaching and research laboratories in microelectronics since 1990. Research efforts are focused on microelectronics from devices to embedded systems and Instrumentation for detection, navigation and nano-satellite programs.

He has 140, published and presented papers at workshops and conferences. He participated to committees of several workshops and conferences as IC-Microelectronics since 1992 and Smart-Systems \& Devices since 2001.

He was the Vice-Dean (2000-2005) and the Dean of Sciences Faculty of Monastir (2008-2011). Since 2005, he is a Member of the University council. He is now a full Professor and the head of the Microelectronics and Instrumentation Lab. 